\title{
FROM THE INSIDE
}

\section{Si me recuerdas (If you remember me)}

\author{
Thanh H. Neville* (1)
}

C 2021 Springer-Verlag GmbH Germany, part of Springer Nature

In November 2020, I met Mr. C as the COVID critical care attending physician. He was a 50-something-yearold man, previously completely healthy. He had already been in the intensive care unit (ICU) for over a week on high-flow oxygen when I started. And during that week, he had learned that his wife and mother had both died from coronavirus disease 2019 (COVID-19) while he was in the hospital. I could not imagine having to grieve for such losses while having to face the uncertainty of his own illness. I treaded lightly when I met him, but I did not ignore the elephant in the room. He told me he had two kids, both in their 20's, so therefore, he still had a lot to live for.

Mr. C never complained even though he was on nearmaximum hi-flow settings and every movement caused his oxygen to drop. He always waved at me with a smiling face through the glass doors when I nervously checked on him multiple times throughout the day. But on my last day, he was maxed out on the hi-flow oxygen and required a face mask on top of that before we could get his saturations to barely $88 \%$. I made the decision to intubate, a decision that I know several nurses and fellows had wanted me to make for a couple of days now. I cowardly asked my resident to call his kids and to tell them that although we will try our best, we could not guarantee that this would end well, and they should video call with him now, when they still can.

I rotated off service the next day, but like many physicians, I continued to look at my patient's trajectory in the medical record. The following days were not easy for Mr. C. Despite lung-protective ventilation strategies and paralysis, he developed a life-threatening pneumothorax that required an emergent chest tube. He went into renal failure and required the initiation of continuous renal replacement therapy. Two weeks after I left service, I received the dreaded note in my in-basket: an end-of-life

${ }^{*}$ Correspondence: tneville@mednet.ucla.edu

David Geffen School of Medicine at UCLA, Los Angeles, CA, USA note that denoted the final wishes that the clinical team implemented for him and his family as part of our 3 Wishes Program [1-3] Wish (1) a zoom goodbye with his son and daughter, Wish (2) a word cloud, Wish (3) fingerprint keychain keepsakes, and Wish (4) to hear his favorite song "Si Me Recuerdas" (If You Remember Me) as he died.

His daughter and son have lost their mother, father, and grandmother in the span of a few weeks.

As the weeks and months of the pandemic went on, my depression that first entered my life during residency has raised its ugly head. I had difficulty sleeping thinking about the tragedies that surround us. Then, in midDecember, near the height of the pandemic, our house burned down and we had to relocate to temporary housing. Ironically, my insomnia was the reason why I heard the sounds of the fire and woke my husband up in the middle of the night. To add insult to injury, the house was then burglarized a few days later. I am sad and angry, but how can my inconvenience and loss of replaceable items compare to the loss of a mother, father, and grandmother all at once?

I doubled the dose of my antidepressant.

I find myself thinking about Mr. C a lot-did I intubate him too early and denied his son and daughter a few more days to interact with him? After all, even though he was severely hypoxic, he was able to interact with his family.? And the intubation certainly did not save his life. Or did I intubate him too late, such that he already had irreversible self-induced lung injury and that's why his lungs were impossible to oxygenate and ventilate on the machine? Did I actually write his death sentence?

I realized I've stopped exercising. I bought one of those bright lights that was supposed to help with seasonal affective disorder. I can no longer sleep without a sleep aid. And even if I was able to fall asleep, early awakenings have started to plague me. During the January surge month, I tried to take walks whenever I can, but these walks were often accompanied by a myriad of confusing

\section{Springer}


emotions: relief that I'm away from the constant beeping of IV pumps and life support machines, envy and resentment that there are happy carefree people going about their lives, and guilt that I am not at a bedside putting out the flames that are engulfing our ICU.

And my collection of tragic stories continued to grow. These stories have not only given me an appreciation for the gift of life, but also the enormity of human suffering that comes with it. If one of my patients died after I rotated off service, I called the family to offer my condolences. It was sometimes weeks before I gathered enough courage, and I am almost always in tears after I hang up. Bearing witness was hard, but how can I possibly compare this pain to the pain families are experiencing? How can I not make these phone calls when families continue to tell me how thankful they are to talk to someone who cared deeply for their loved one-at a time when they themselves could not be at the bedside? I will always remember my conversation with Mr. C's son. He told me he was just on the verge of a breakdown right before I called him. I spoke to him for nearly an hour-and he wondered out loud if his father in heaven had signaled to me to call him at that very moment.

And I think of the song Mr C's kids wanted him to hear as he died. "Si me recuerdas". If You Remember Me.
The truth is-I don't know how to forget.

\section{Acknowledgement}

I thank Arielle Sommer for inviting me to be open, fallible, and vulnerable and to tell this story for the first time as part of the "UCLA COVID StorySLAM".

\section{Declarations}

Conflicts of interest

All authors declared that they have no conflict of interest.

\section{Publisher's Note}

Springer Nature remains neutral with regard to jurisdictional claims in published maps and institutional affiliations.

Received: 3 March 2021 Accepted: 17 March 2021

Published online: 6 April 2021

\section{References}

1. Vanstone M, Neville TH, Clarke FJ et al (2020) Compassionate end-of-life care: mixed-methods multisite evaluation of the 3 wishes project. Ann Intern Med 172(1):1-11

2. Neville TH, Clarke F, Takaoka A et al (2020) Keepsakes at the end of life. J Pain Symptom Manage 60(5):941-947

3. Neville TH, Agarwal N, Swinton M et al (2019) Improving end-of-life care in the intensive care unit: clinicians' experiences with the 3 wishes project. J Palliat Med 22(12):1561-1567 